\title{
La compra pública de innovación: retos y oportunidades para el desarrollo de la I+d+i desde la demanda pública(*)
}

\section{Public procurement of innovation: challenges and opportunities for the development of R\&D\&I from public demand}

\author{
Juan Antonio Carrillo Donaire ${ }^{(*)}$ \\ Universidad de Sevilla (Sevilla, España)
}

\begin{abstract}
Resumen: La compra pública de innovación (CPI) es una modalidad de compra que pretende aumentar la inversión en I+D+i y la mejora de los servicios públicos desde el lado de la demanda, y constituye una apuesta estratégica de la OCDE y de la Unión Europea, especialmente impulsada en los últimos años. Los contratos de CPI presentan una serie de peculiaridades jurídicas en su tramitación que los hacen singularmente complejos, tanto en su fase de preparación y adjudicación como de ejecución, lo que requiere un proceso de aprendizaje y de adaptación para los gestores públicos y para el propio mercado, cuyas claves jurídicas se destacan y comentan pormenorizadamente en este trabajo.
\end{abstract}

Palabras clave: Contratación pública - Compra pública de innovación - Compra pública precomercial - Derecho Administrativo

\begin{abstract}
Public procurement of innovation (PPI) is a purchasing modality that aims to increase investment in R\&D and the improvement of public services from market demand side. It is a strategic commitment of the OECD and the European Union, especially promoted in recent years. PPI contracts present legal peculiarities in their processing that make them uniquely complex, from their preparation til their execution, which requires a learning and adaptation process for public managers and for the market itself, whose legal keys are highlighted in this paper.
\end{abstract}

Keywords: Public procurement - Public procurement of innovation - Precommercial procurement - Administrative Law

$\left(^{*}\right) \quad$ Nota del Editor: Este artículo fue recibido el 31 de enero de 2021 y su publicación fue aprobada el 21 de marzo de 2021.

${ }^{* *}$ Abogado por la Universidad de Sevilla (Sevilla, España). Doctor en Derecho por la Universidad de Sevilla. Catedrático de Derecho Administrativo en la Universidad de Sevilla. Consejero electo del Consejo Consultivo de Andalucía. Especialista en Seguridad y Calidad industrial, Riesgos en el proceso, Derecho patrimonial público, Contratación administrativa, Expropiación forzosa y Responsabilidad patrimonial de las administraciones públicas e Inteligencia Artificial. ORCID: https://orcid.org/0000-0002-3174-5254 Correo electrónico: donaire@us.es. 


\section{Introducción}

La compra pública de innovación (en lo sucesivo, CPI) es una novedosa medida de fomento orientada a que las Administraciones adquieran productos y servicios que aún no existen en el mercado, o que mejoran los existentes, para cubrir sus necesidades con las soluciones tecnológicas e innovadoras que se adaptan de forma más eficiente y sostenible a las necesidades públicas. A través de esta modalidad de compra pública se persigue una doble finalidad: de un lado, fomentar la actividad innovadora e investigadora de las empresas y contratistas desde el lado de la demanda pública, por considerarse la I+D+i un factor estratégico de competitividad; y, de otro lado, mejorar la prestación de los servicios públicos, tanto su calidad como el nivel de satisfacción de la ciudadanía. Con este doble objetivo, la OCDE y la Unión Europea llevan años apostando por la CPI como fórmula idónea para fomentar la innovación en el mercado.

Los procedimientos de CPI no siguen las pautas ordinarias de la contratación pública. En estos casos, tanto la preparación y adjudicación del contrato como su ejecución han de adaptarse a una forma de comprar que se basa en unas premisas singulares que en buena medida cuestionan los principios clásicos de la contratación: objeto cierto, precio determinado, inmediatez y corto plazo, riesgo y ventura del empresario, etc., evolucionado hacia modelos en los que prima la negociación con el mercado y el reparto de riegos ante la incertidumbre que inevitablemente conlleva la adquisición de innovación y la apuesta por la investigación aplicada.

Así, la peculiaridad de las prescripciones técnicas que han de reflejar los Pliegos para comprar algo inexistente o mejorable requiere adaptar la cultura de la innovación por la vía de las funcionalidades y del rendimiento previsible y futuro de algo que se pretende crear o mejorar para luego comprarlo, y que habrá de testarse en un modelo de prueba-error con medición del grado de éxito. En la selección del contratista también se prevén fases de definición progresiva del objeto del contrato (pues, en puridad, éste no está definido de forma cerrada en los Pliegos), y del propio precio, que puede fluctuar a lo largo de la vida del contrato en razón del éxito o de la intensidad de la investigación desarrollada. También es un elemento característico de la CPI la posibilidad de eliminación progresiva de ofertas y adjudicatarios que, no obstante, pueden ser objeto de retribución parcial si la innovación aportada es considerada o ha representado algún elemento relevante para la solución final. Todas esas peculiaridades requieren un procedimiento de adjudicación adaptado a las mismas, que la Directivas europeas de contratación pública adoptadas en 2014 llaman de "asociación para la innovación", aunque caben otros procedimientos para la CPI que, no obstante, deberán dar cabida a la posibilidad de negociación en razón del objeto natural de los contratos de innovación.
Finalmente, en la ejecución del contrato tampoco pueden jugar del mismo modo las garantías ordinarias de la contratación pública; en particular las relativas al riesgo y ventura del contratista, al grado de cumplimiento del objeto del contrato, a la confidencialidad de la información o al reparto de los riesgos y los beneficios entre la Administración adjudicadora y el contratista. La alteración del riesgo y ventura empresarial no sólo consiste en que la Administración contratante asuma conjuntamente las cargas imprevisibles de la CPI, sino que también puede incluir la distribución de los beneficios resultantes en base al principio de libertad de pactos. Y todo ello por la presencia transversal y permanente del elemento capital de la innovación en este tipo de contratos.

En definitiva, el éxito de la CPI reside en el requilibrio de fuerzas en que las empresas vean a la Administración como un socio fiable para emprender proyectos innovadores y viceversa. El comprador público, modulando la idea de prerrogativa, tendrá que posicionarse como un socio dispuesto a negociar cada uno de los aspectos dimanantes de la contratación de innovación. Todos estos factores obligan a un cambio de mentalidad de la Administración y en los gestores públicos a favor de una $I+D+i$ europea realmente competitiva.

No es un reto pequeño, ya que de todos es sabido que ningún cambio de mentalidad en la gestión pública está exento de inercias contrarias y de recelos; máxime cuando la tramitación de los procedimientos de CPI presume anticipar la planificación y conlleva un incremento de la carga de trabajo y del grado de exposición que acompaña cualquier procedimiento negociado, unido a la incertidumbre y el más elevado riesgo que implica un proceso de compra de un producto o servicio inexistente en el mercado. El bajo empleo del procedimiento de asociación para la innovación a fecha de hoy es un claro indicio de lo dicho. En un contexto así, no es de extrañar que los gestores públicos se refugien en la confortabilidad de la contratación normalizada del procedimiento abierto que, aunque lleno de garantías y de transparencia, no consigue los niveles de satisfacción y rendimiento deseables cuando se trata de desarrollar nuevas tecnologías 
aplicadas a productos y servicios realmente innovadores, verdaderamente eficientes y adaptados a las necesidades reales de los intereses generales concernidos en cada acto de compra pública.

Sin embargo, desde la OCDE y la UE se promueve una visión de la CPI como una oportunidad para que el gestor público supere el miedo a las barreras de la innovación, promoviendo la capacitación para aplicar una nueva metodología más flexible, pero acorde a los principios generales de la contratación pública, en orden a hacer de la innovación una realidad tangible y un elemento de modernización de la economía.

\section{Concepto y objetivos de la compra pública de innovación}

El desarrollo explosivo y exponencial de las tecnologías de la información, la digitalización de la economía y la liberalización de los mercados son los algunos de los factores principales de lo que se ha denominado la Cuarta Revolución Industrial(1). Estos fenómenos han trastocado la percepción de la realidad económica y social, provocando que la referencia central sobre la que se asienta el sistema económico mundial mute del paradigma de la búsqueda de estabilidad al de cambio continuo y sostenibilidad. Bajo estos parámetros, el equilibrio es una pretensión dinámica y cambiante, muy alejada de la ideas de seguridad y previsibilidad. Las nociones de adaptabilidad al cambio continuo, resiliencia, y sostenibilidad son dos importantes vectores de la economía globalizada, siendo la innovación una herramienta clave para la articulación del equilibrio entre ambas.

Los retos globales de la competitividad y productividad mundial, el cambio climático, la contaminación, la pobreza o la exclusión social necesitan de la innovación para procurar mayor estabilidad macroeconómica e institucional, y hacer más eficiente y sostenible las infraestructuras, el tráfico de mercancías y servicios, el mercado laboral, la prestación de servicios básicos a la ciudadanía y el impulso del crecimiento empresarial.

En una aproximación al significado de innovación, el Manual de Oslo contiene una "Guía para la Recogida e Interpretación de Datos sobre Innovación”, elaborada conjuntamente por la Organización para la Cooperación y el Desarrollo Económico
(OCDE) y la Comisión Europea (Eurostat), que define la innovación como "la introducción de un nuevo, o significativamente mejorado, producto (bien o servicio), de un proceso, de un nuevo método de comercialización o de un nuevo método organizativo, en las prácticas internas de la empresa, la organización del lugar de trabajo o las relaciones exteriores" (OCDE \& Eurostat, 2005, p. 56).

Con esta definición, generalmente aceptada, el mencionado Manual delimita cuatro ámbitos de innovación: producto, proceso, mercadotecnia y organización. A partir de esa delimitación, la OCDE y la Comisión Europea se sirven del criterio tecnológico para distinguir entre innovación de producto y proceso (innovación tecnológica) e innovación de mercadotecnia y organizativa (innovación no tecnológica).

Dentro de la innovación tecnológica, el Manual de Oslo delimita la innovación de producto a "la introducción de un bien o de un servicio nuevo, o significativamente mejorado, en cuanto a sus características o en cuanto al uso al que se destina. Esta definición incluye la mejora significativa de las características técnicas, de los componentes y los materiales, de la informática integrada, de la facilidad de uso u otras características funcionales" (OCDE \& Eurostat, 2005, p. 58).

Este concepto de innovación, que ha calado en el Derecho europeo de la contratación pública, como veremos, comprende productos y servicios obtenidos a partir de conocimientos y tecnologías inexistentes hasta el momento, así como también pueden ser resultado de combinaciones de conocimientos y tecnologías ya existentes ${ }^{(2)}$. Este es el marco conceptual en el que entra en juego la contratación pública como medio idóneo para satisfacer los objetivos propuestos por la OCDE y la Unión Europea en orden a

(1) Véase en SCHWAB, K. (2016). The Fourth Industrial Revolution y The Global Competitiveness Report (2016-2017). World Economic Forum.

(2) En innegable la influencia de esta definición en el concepto de innovación plasmado, por primera vez, por el artículo 2.2 de la Directiva 2014/24/UE, según el cual:

[La compra de innovación consiste en la] adquisición de un producto, servicio o proceso nuevos o significativamente mejorados, que incluye, aunque no se limita a ellos, los procesos de producción, edificación o construcción, un nuevo método de comercialización o un nuevo método de organización de prácticas empresariales, la organización del lugar de trabajo o las relaciones exteriores, entre otros con el objetivo de ayudar a resolver desafíos de la sociedad o a apoyar la Estrategia Europa 2020 para un crecimiento inteligente, sostenible e integrador. 
garantizar un desarrollo continuo y sostenible de la realidad económica y social.

En este orden de consideraciones, la compra pública es un importante motor de realización de políticas públicas sustantivas, favorecedoras de determinadas orientaciones del mercado, sin perder de vista el objetivo primario de las Directivas de contratación de mejorar la eficiencia de la política de compras del sector público. Tal y como prevé el artículo 1 de la Ley 9/2017, de 8 de noviembre, de Contratos del Sector Público (en adelante, LCSP), por la que se transponen al ordenamiento jurídico español las Directivas del Parlamento Europeo y del Consejo 2014/23/UE y 2014/24/UE, de 26 de febrero de 2014:

[La contratación pública radica en] una eficiente utilización de los fondos destinados a la realización de obras, la adquisición de bienes y la contratación de servicios mediante la exigencia de la definición previa de las necesidades a satisfacer, la salvaguarda de la libre competencia y la selección de la oferta económicamente más ventajosa.

En este contexto se inscribe la contratación pública de innovación (CPI) o public procurement of innovation (PPI) como una actuación administrativa de fomento del I+D+i orientada a potenciar el desarrollo de nuevos mercados innovadores desde el lado de la demanda a través del instrumento de la contratación pública. La CPI promueve, así, el desarrollo tecnológico como medio efectivo para obtener productos y servicios novedosos y mejor adaptados a las necesidades de la Administración a partir de la colaboración público-privada. En el fondo, no es más que una manifestación concreta más de que la compra pública ha dejado de ser una actividad adjetiva al desarrollo de políticas sustantivas (que necesitan productos, servicios y obras) para convertirse, en sí misma, en una política pública orientada a la satisfacción de objetivos de políticas públicas sustantivas. Desde esta convicción, la Directiva 2014/24/UE del Parlamento Europeo y del Consejo, de 26 de febrero de 2014, sobre contratación pública, por la que se deroga la Directiva 2004/18/CE, apuesta por la contratación pública como el instrumento idóneo para fomentar la innovación en determinados ámbitos como el medio ambiente, la eficiencia energética, el empleo, el apoyo a los PYMEs, la salud y la seguridad.

La CPI se ha concebido para animar, de un lado, a los poderes adjudicadores a que demanden soluciones innovadoras mediante la licitación de contratos de I+D y para estimular, de otro lado, al sector privado a que oriente su actividad a la innovación como factor de competitividad.

Ha de dejarse sentado, desde un principio, que la CPI no es un tipo contractual, ni un procedimiento de contratación.
Se trata, antes bien, de una estrategia de compra a disposición de las políticas públicas de innovación. Por tanto, cuando hablamos de compra pública de innovación nos estamos refiriendo a una actuación de fomento de la innovación realizada desde el sector público, a través de la contratación administrativa, que persigue mejorar los servicios públicos, impulsar la innovación empresarial e internacionalizar la innovación local.

\section{La innovación como compra pública estratégica en el marco OCDE y europeo}

\section{1. Ámbito internacional}

En el contexto anteriormente descrito, los Gobiernos se sienten proclives a emprender políticas activas de innovación que hagan compatible el crecimiento económico y el desarrollo sostenible. Estas políticas se conciben y diseñan con el objetivo de resolver retos presentes y futuros; por lo que es conveniente dotarlas de mecanismos de coordinación entre los distintos niveles de la Administración Pública y de fórmulas estandarizadas de sistemas de colaboración entre el sector público y privado.

Los Estados necesitan políticas activas de innovación que fijen las prioridades esenciales y se ajusten a un modelo de especialización científica, tecnológica y productiva capaz de capitalizar todas aquellas oportunidades que vayan surgiendo a partir de la evolución de sus propias capacidades.

Para medir la relación entre la innovación, I+D y la contratación pública resultan ilustrativas las estimaciones actuales sobre la posición que ocupan los países de la UE, y particularmente España, en el panorama internacional.

La evaluación de la OCDE de 2019 sobre la innovación europea sitúa la media de los países Europeos por debajo del liderazgo norteamericano y asiático(3). Por su parte, España se encuentra lejos de la cabeza en

(3) Véase en Schwab, K. (2019). The Global Competitiveness. World Economic Forum. http://www3.weforum.org/docs/WEF_ TheGlobalCompetitivenessReport2019.pdf 
materia de innovación en Europa, con la especial detección por parte de la OCDE de la insuficiente capacidad de innovación como el cuarto mayor problema para impulsar el crecimiento empresarial, por debajo del sistema tributario, la ineficiente gobernanza burocrática y la restrictiva regulación laboral. La persistente existencia de estos problemas, junto a la falta de actuación de la Administración Pública y su compleja coordinación con el sector privado en aras de lograr mejores cuotas en innovación, sitúa a nuestro país algo por debajo de la media internacional y europea.

En lo relativo a la contratación pública, la OCDE estima que el peso medio relativo de esta actividad oscila entre un $13 \%$ y un $20 \%$ del PIB mundial(4). Concretamente, en los países desarrollados la contratación pública ese impacto está por encima del $15 \%$ del PIB, situándose en el caso español en el $18,5 \%$, lo que en términos cuantitativos significa un total de 194000 millones de euros anuales, algo por encima de los 4000 euros anuales per cápita.

A la vista de estos datos no puede sino concluirse que la actividad de contratación es capital, en su carácter puramente instrumental, para el desarrollo de servicios básicos para la ciudadanía. Ciertamente, el aprovisionamiento de bienes y servicios por parte de las Administraciones públicas es un factor determinante en aspectos esenciales de la vida diaria como la sanidad, la educación, la justicia, la seguridad o el transporte. Como correlato de ello, organismos internacionales como la propia OCDE o el Banco Mundial consideran que la integridad en la contratación administrativa es esencial para que los ciudadanos no pierdan la confianza en el sector público ${ }^{(5)}$.

Con estas estimaciones, la OCDE se ha propuesto firmemente promover un crecimiento continuado, menos contaminante y más justo, promoviendo la innovación más allá de la ciencia y la tecnología, y extendiendo su aplicación a la educación, el crecimiento empresarial y la creación de empleo. Los propósitos de la OCDE se plasmaron hace tiempo en The OECD Innovation Strategy: Getting Start on Tomorrow de 2010, donde se describieron las cinco grandes líneas de actuación: (i) desarrollar la capacidad innovadora de las personas mediante la educación y la formación, (ii) liberar el potencial innovador, (iii) aplicar y financiar adecuadamente la investigación, (iv) aplicar la innovación como solución a los retos, presentes y futuros, y (v) perfeccionar las políticas de innovación.

Estas líneas de actuación comprenden, entre otras, a la CPI como instrumento con el que los compradores públicos y los operadores privados podrán obtener resultados de $1+D+i$ conjugando innovación y contratación pública.

\section{2. Ámbito europeo}

En el ámbito comunitario, la Unión Europea puso en práctica un Programa Marco sobre las actividades de investigación e innovación para el período 2014-2020, denominado "Estrategia Europea 2020", posteriormente sustituida por el eje equivalente del nuevo marco de la Agenda 2030 para el desarrollo sostenible en Europa, que se erige como la planificación de referencia para las políticas de innovación de los Estados miembros.

El programa concebido para impulsar la estrategia "Horizonte 2020" y la iniciativa "Unión por la innovación" apostó por un modelo de crecimiento inteligente, sostenible e integrador del conjunto de la sociedad europea a partir de tres pilares básicos relativos a abordar los principales retos sociales, promover el liderazgo industrial en Europa y consolidar la excelencia de su base científica. Los fondos de este programa continúan en ejecución durante 2021, donde serán sustituidos por el nuevo Marco Presupuestario 2021-2027 centrado en los objetivos de la Agenda 2030, que refuerza la apuesta europea por la innovación.

Con un presupuesto total de 77.028 millones de euros y una inversión inicial en I+D+i del $3 \%$ del PIB de la Unión Europea, Horizonte 2020 ha agrupado e impulsado las actividades financiadas por el VII Programa Marco de Investigación y Desarrollo, las acciones de innovación del Programa Marco para la Innovación y la Competitividad y las acciones del Instituto Europeo de Innovación y Tecnología. La clave de estos programas europeos de innovación radica en que integran todas las fases de la investigación y la innovación, esto es desde la generación del conocimiento hasta las labores comerciales contemplando específicamente el apoyo directo a la CPI.

A través de la CPI Europa se propone reducir de forma considerable el vacío y la desconexión, siempre existente, entre los procesos de investigación e innovación y la tecnología y los compradores públicos. Este propósito requiere el desarrollo de los

(4) Véase en OCDE. (s/f). Public Procurement for Sustainable and Inclusive Growth. Enabling reform through evidence and peer reviews. https://www.oecd.org/gov/ethics/Public-Procurement-for\%20Sustainable-and-Inclusive-Growth_Brochure.pdf

(5) Véase en OCDE. (2009). Principles for Integrity in Public Procurement. 
mecanismos de coordinación de los organismos públicos responsables en materia de contratación pública y las fórmulas de colaboración con los agentes privados, así como el régimen que han asumir Administración Pública y empresas para soportar y compartir conjuntamente los riesgos y beneficios derivados de $++D+i$. Los análisis más recientes de evaluación de la aplicación de estos objetivos que ha acometido la Comisión Europea muestran que la CPI es todavía en reto deficientemente alcanzado en el mercado europeo de la contratación, pese al esfuerzo inversor de la UE en este campo ${ }^{(6)}$.

Para facilitar la consecución del reto que supone la CPI, Horizonte 2020 ha financiado los proyectos en todas sus fases, desde la investigación al mercado, aplicando un porcentaje único de financiación mediante reembolso de los costes subvencionables, integrados por los costes directos y un tipo fijo del $25 \%$ para los costes indirectos. Esta financiación podrá llegar al $100 \%$ del total de los costes subvencionables en las actividades de investigación e innovación y hasta un 70\% en caso de que las entidades participantes en el proyecto financiado persigan ánimo de lucro.

El ánimo de potenciar una definitiva apuesta nacional por el empleo de estos fondos en proyecto de CPI por los Estados miembros se plasmó en la aprobación de unas "Orientaciones sobre la contratación pública en materia de innovación" en mayo de 2018 por la Comisión Europea [DOUE C (2018) 3051 final], adoptadas en el contexto de la Comunicación de la Comisión sobre la "Nueva agenda europea de investigación e innovación: una oportunidad para que Europa trace su futuro"(7).

\section{3. Ámbito español}

La sensibilización sobre el valor estratégico de la compra pública de tecnología innovadora tuvo una incipiente respuesta en la aprobación en 2009 de la "Estrategia Española para el Desarrollo Sostenible", con la que España aceleraba la transformación del modelo productivo con un conjunto de iniciativas legislativas, reglamentarias y administrativas orientadas a garantizar un crecimiento sosteniblemente económico, medioambiental y social.

Tales iniciativas se materializaron en dos normas concretas: la Ley 14/2011, de 1 de junio, de la Ciencia, la Tecnología y la Innovación (LCTI) y la Ley 2/2011, de 4 de marzo, de Economía Sostenible (LES); que introdujeron el concepto legal de CPI en la legislación de contratos del sector público. Complementándose con mecanismo de planificación: la llamada Estrategia Estatal de Innovación (E2i), para el periodo 2010-2015, que tuvo continuidad en el marco de la renombrada como Estrategia Española de Ciencia y Tecnología y de Innovación 2013-2020, seguida de otra equivalente para el periodo 2021-2027(8).

En síntesis, este conjunto de medidas ha asentado la idea de que, para impulsar la innovación, la contratación pública debía aplicarse de modo especial, y hasta distinto, en aquellos sectores económicos en los que la Administración Pública ostenta una posición dominante, en orden a cumplir con los objetivos europeos y nacionales tendentes a posicionar a Europa en la cumbre de la innovación internacional. Como sintéticamente apunta la Estrategia española de Ciencia, Tecnología e Innovación vigente:

La innovación sistémica acercará y hará partícipe a la sociedad de los resultados de la innovación y de sus procesos. En este sentido, cabe destacar que se fomentará la Compra Pública de Innovación (CPI) desde el ámbito público (AGE, CCAA, entidades locales, empresas públicas, universidades, etc.) que convertirá a las AAPP en elementos tractores de actividad innovadora (Ministerio de Ciencia e Innovación, 2021, p. 37).

Con esta estrategia se definieron las líneas estratégicas sobre CPI, las cuales han cuajado también en algunas las Comunidades Autónomas y en algunas Administraciones locales, que han aprobado sus propias estrategias de CPI.

\section{Modalidades de la compra pública de innovación en función del estado previo de la técnica y del grado de desarrollo de I+d+i necesario en cada caso}

En función del grado de innovación necesaria para desarrollar u producto o un servicio se distingue habitualmente entre la llamada compra pública pre-comercial y la compra pública de tecnología innovadora; distinción que tiene efectos jurídicos significativos.

La compra pública pre-comercial (CPP) o pre-commercial procurement $(P C P)$ es un

(6) Véase en https://ec.europa.eu/digital-single-market/en/news/online-consultation-benchmarking-national-innovation-procurementpolicy-frameworks

(7) Véase en http://data.consilium.europa.eu/doc/document/ST-8921-2018-INIT/es/pdf

(8) Véase en https://www.ciencia.gob.es/stfls/MICINN/Ministerio/FICHEROS/EECTI-2021-2027.pdf 
contrato de servicios de I+D en el que el comprador público no se reserva los resultados innovadores para su propio uso en exclusiva, sino en el que comparte con la empresa adjudicataria los riesgos y beneficios derivados del proceso de creación, desarrollo y ejecución de soluciones inexistentes hasta el momento en el mercado ${ }^{(9)}$. Su objeto es, por regla general, llevar una idea al desarrollo a partir del desarrollo de pruebas y ensayos y al diseño de prototipos.

Por su parte, la compra pública de tecnología innovadora (CPTI) o public procurement of innovative technology (PPIT) consiste en la contratación de un bien o servicio innovador e inexistente hasta el momento, pero cuyo desarrollo y ejecución puede llevarse a cabo en un período de tiempo razonable a partir de prototipos preexistentes. El objeto de esta compra es la adquisición de tecnología nueva o mejorada que ya ha pasado algún proceso previo de I+D. Con dicha adquisición, la Administración Pública se posiciona como un cliente de lanzamiento de aquellos bienes y servicios que, disponiendo de un prototipo o modelo, aún no han alcanzado la fase comercial(10). A diferencia de la CPP, la CPTI queda incluida en el ámbito de aplicación de la Directiva 2014/24/UE y de la LCSP(11).

\subsection{Singularidades de la compra pública precomercial} La CPP tiene por objeto la contratación de servicios de I+D+i para la consecución de soluciones innovadoras inexistentes en el mercado. En principio, estos contratos quedan excluidos del ámbito de aplicación de la LCSP en su artículo 8, en aplicación de la exclusión amparada por la Directiva 2014/24/UE en su artículo $14^{(12)}$. No obstante, la LCSP establece tres requisitos para que los contratos públicos de investigación e innovación puedan ser incluidos en su regulación.

En primer lugar, los contratos deberán atender a los códigos de vocabulario establecidos expresamente en el precepto ${ }^{(13)}$, esto es: servicios de investigación y desarrollo y servicios de consultoría conexos, servicios de investigación y desarrollo experimental, servicios de investigación, servicios de laboratorio de investigación, servicios de investigación marina, servicios de desarrollo experimental, diseño y ejecución en materia de investigación y desarrollo, estudio de pre-viabilidad y demostración tecnológica y servicios de ensayo y evaluación.

En segundo lugar, los beneficios derivados de la innovación tendrán que corresponder en exclusiva al comprador público quedando reservada la utilización del bien o servicio, fruto del proceso de I+D+i, para él mismo. Ésta es la exigencia que supone un apartamiento claro del régimen prototípico de la CPP, pues precisamente una de sus características esenciales consiste en la gestión conjunta de los riesgos y beneficios por parte de los agentes, públicos y privados, intervinientes en la contratación.

En tercer y último lugar, la LCSP añade un segundo requisito adicional para la inclusión de estos contratos en su ámbito de aplicación: que la remuneración corresponda al poder adjudicador en su totalidad.

Con independencia de que puedan quedar fuera de la normativa sobre contratación pública si no se dan las condiciones citadas, las contrataciones de CPP vienen obligadas a cumplir los principios generales de la contratación administrativa (libertad de

(9) Comunicación de la Comisión al Parlamento Europeo, al Consejo, al Comité Económico y Social Europeo y al Comité de las Regiones (2007). La contratación precomercial: impulsar la innovación para dar a Europa servicios públicos de alta calidad y sostenibles (COM/2007/0799 final). Eur-Lex.

(10) Véase en López, A. M. (2014). La compra pública innovadora en los sistemas europeo y español de contratación pública. En J. Pernas (coord.), Contratación Pública Estratégica (pp. 213-248). Aranzadi Thomson Reuters.

(11) La diferencia entre una y otra modalidad de compra de innovación tiene un tratamiento diferente desde la perspectiva de la aplicación de la legislación de contratos del sector público, por cuanto la primera de las referidas modalidades, la compra precomercial, es, en principio, un contrato excluido de la LCSP, salvo que los beneficios pertenezcan exclusivamente al poder adjudicador para su utilización en el ejercicio de su propia actividad y, además, el servicio prestado sea remunerado íntegramente por aquel (artículo 8 LCSP). Así, pues, el establecimiento de un régimen compartido de riesgos y beneficios entre los contratantes constituye una de las condiciones esenciales para la celebración de este contrato de servicios de innovación que queda expresamente excluido de la Directiva sobre contratación pública y de la LCSP.

(12) Como expresa el Cdo. 47 de la Directiva 2014/24/UE sobre la exclusión de la CPP, diciendo que, "Debe señalarse que en la Comunicación de la Comisión de 14 de diciembre de 2007 titulada 'La contratación precomercial: impulsar la innovación para dar a Europa servicios públicos de alta calidad y sostenibles' se expone una serie de modelos de contratación en relación con la prestación de dichos servicios de I+D que no entran en el ámbito de aplicación de la presente Directiva".

(13) Reglamento (CE) 213/2008 de la Comisión, de 28 de noviembre de 2007, que modifica el Reglamento (CE) no 2195/2002 del Parlamento Europeo y del Consejo, por el que se aprueba el Vocabulario común de contratos públicos (CPV), y las Directivas 2004/17/CE y 2004/18/CE del Parlamento Europeo y del Consejo sobre los procedimientos de los contratos públicos, en lo referente a la revisión del CPV. 
acceso, publicidad y transparencia, no discriminación e igualdad de trato, integridad, libre competencia y selección de la oferta económicamente más ventajosa) y ello, por las razones esgrimidas por el Tribunal de Justicia de la Unión Europea desde su Sentencia de 13 de octubre de 2005 (asunto C-458/03), Parking Brixen $\mathrm{GmbH}$ contra Gemeinde Brixen y Stadtwerke Brixen $A G$, a propósito de la situación de aquellos contratos públicos que quedan excluidos de la normativa sobre contratación pública, en la que el Alto Tribunal europeo -en línea con resoluciones posteriores- resuelve haciendo extensiva la aplicación de los principios generales de la contratación pública, recogidos en el TFUE, a todos los contratos que sean celebrados por la Administración Pública.

La primera referencia que el ordenamiento jurídico español hizo sobre la CPP fue con ocasión de la reforma de la derogada Ley 30/2007, de 30 de octubre, de Contratos del Sector Público, operada por la Ley $2 / 2011$, de 4 de marzo, de Economía Sostenible, que, como dijimos, introducía un nuevo apartado en el artículo 4.1 del texto Refundido de la Ley de Contratos del Sector Público (TRLCSP) bajo la letra r), que en sede de "negocios y contratos excluidos" decía así:

Los contratos de investigación y desarrollo remunerados íntegramente por el órgano de contratación, siempre que éste comparta con las empresas adjudicatarias los riesgos y los beneficios de la investigación científica y técnica necesaria para desarrollar soluciones innovadoras que superen las disponibles en el mercado. En la adjudicación de estos contratos deberá asegurarse el respeto a los principios de publicidad, concurrencia, transparencia, confidencialidad, igualdad y no discriminación y de elección de la oferta económicamente más ventajosa.

Pese a que no había en esta previsión una alusión expresa a la compra pública pre-comercial, el Informe 13/11, de 10 de mayo de 2012, de la Junta Consultiva de Contratación Administrativa del Estado sobre el régimen derivado de los contratos de $1+D+i$, interpretó que el precepto aludía precisamente a los contratos de I+D+i propios de la $\mathrm{CPI}^{(14)}$. Además, la Ley 30/2007 contemplaba otra referencia a la CPP en su artículo 38, también introducido por la Ley de Economía Sostenible, dedicado a las partidas presupuestarias consignadas a los contratos previstos en el artículo 4.1 r) de la Ley 30/2007(15).

En cuanto a la inclusión de la CPP en el TRLCSP, su artículo 4.1 r) reproduce lo dispuesto en la norma anterior y su
Disposición Final quinta alude expresamente a la CPI constituyendo la primera referencia expresa en nuestra normativa sobre contratos públicos. Respecto a la vigente LCSP, su artículo 8 excluye de su ámbito de aplicación, como se ha dicho, los contratos de I+D+i en los términos antes reseñados. Lo que en modo alguno impide que estos contratos de CPP incorporen elementos propios de la contratación pública en las fases de preparación y adjudicación (Consultas Preliminares al Mercado, elaboración de Pliegos, definición de requisitos de solvencia, criterios de adjudicación y condiciones especiales de ejecución, etc.). De hecho, el procedimiento de "asociación para la innovación" específicamente previsto para los contratos de CPI que sí se someten a la LCSP tiene su origen en la práctica contractual asentada de los contratos de desarrollo de la innovación de naturaleza pre-comercial, destinados al desarrollo de productos o servicios inexistentes en el mercado.

En definitiva, los contratos de $1+D+i$ comprendidos en la CPP carecen de presencia positiva en Derecho comunitario y español a causa de un motivo fundamental. La propia naturaleza de estos contratos obliga a las partes a acordar un régimen de riesgos y beneficios en el que conjuntamente soporten las cargas derivadas de los procesos de $1+D+i \mathrm{y}$, en consecuencia, se beneficien de los resultados obtenidos en proporción a la magnitud de su apuesta en el proyecto.

Otro aspecto de la CPP a tener en cuenta radica en que la retribución del contrato de I+D+i no puede depender de los resultados sino del proceso de innovación en sí, por lo que el poder adjudicador deberá abonar una cuantía fija en función de la estimación que las partes realicen sobre las posibles fluctuaciones de los riesgos y los beneficios.

(14) El Informe 13/11 de la Junta Consultiva de Contratación Administrativa del Estado (2012) señala que:

Como vemos, según la Directiva comunitaria, los contratos de investigación y desarrollo a los que se refiere la consulta son, en efecto, contratos de servicios y en este mismo sentido, aparecen dentro de otros documentos que nos sirven para interpretar la normativa en cuestión, como es el Libro Verde, a nivel comunitario, o la Guía de Compra Pública Innovadora, a nivel nacional. La identificación en estos documentos de este tipo de contratos como contratos de servicios, nos llevan a la conclusión de que la ley española, aun cuando no lo señala expresamente, también se refiere a contratos de servicios, cuando regula los contratos de investigación y desarrollo dentro del artículo 13, 2, b), en lógica consecuencia con el contenido de la Directiva 2004/18/CE (considerando 2).

(15) Según el cual, "El Consejo de Ministros, mediante acuerdo, fijará dentro de los presupuestos de cada Departamento ministerial y de cada Organismo público vinculado con o dependiente de la Administración General del Estado, las cuantías necesariamente destinadas a la financiación de contratos a los que hace referencia el artículo 4.1. r) de la Ley 30/2007, de 30 de octubre, de Contratos del Sector Público. Una parte de las mismas podrá reservarse a pequeñas y medianas empresas innovadoras". 
La CPP rompe el esquema clásico de contratos públicos por su propia esencia: la compra de ideas innovadoras que ni existen en el momento de la contratación, ni disponen si quiera de una realidad física. Pudiera decirse que rompe la idea misma del contrato, desde su concepción en la teoría general del Derecho, pues -de inicio- ni siquiera hay cosa cierta, ni desde luego precio conocido. Por ello, la idiosincrasia de este contrato de $I+D+i$ conduce a una multitud de características singulares que apuntaremos a continuación.

Tal y como acabamos de exponer, la CPP queda, en principio, excluida de la normativa de contratación pública, por lo que la elección del procedimiento adecuado es compleja. Ordinariamente, la entidad adjudicadora tendrá que convocar públicamente la licitación en un procedimiento ad hoc que podrá comprender varias fases, a las que posteriormente haremos alusión al hablar de los contratos de CPI incluidos en la LCSP. Una primera fase en la que el comprador público organice un encuentro con el mercado o meet the market event lanzando consultas preliminares al mercado y anuncios de información previa, según disponen los artículos 115 y 134 de la LCSP, respectivamente, con el fin de elaborar un mapa de demanda temprana que ofrezca la definición del bien o el servicio objeto del contrato así como del proceso de $\mathrm{I}+\mathrm{D}+\mathrm{i}$ pretendido. En ocasiones, el objetivo de esta fase preliminar puede tener una doble vertiente, ya que, tanto la autoridad contratante puede consultar al mercado como recibir ofertas no solicitadas, esto es, que la empresa planteé por sí misma una solución a una necesidad futura. Una segunda fase consistente en un estudio de viabilidad sobre las propuestas seleccionadas fruto del encuentro con el mercado. Dicho estudio tendrá que ser limitado por un plazo y dotación determinada. Y una tercera fase en la que se contratará la propuesta cuyo estudio haya mostrado la mejor viabilidad de acuerdo a la investigación aplicada y al desarrollo experimental que requiere la oferta en cuestión.

Con el respeto a los principios generales de la contratación pública antes aludidos, el diálogo técnico entre el poder adjudicador y las empresas interesadas podrá iniciarse con carácter previo a la publicidad de la convocatoria mediante las consultas preliminares al mercado.

Esta posibilidad conlleva que la Administración no pueda determinar la idoneidad de la propuesta debiendo partir de la definición del problema a resolver por los licitadores. Al contrario que en cualquier contrato público, la licitación de la CPP no parte del objeto sino de la causa que origina la contratación de I+D+i, esto es, el problema técnico a solucionar.

Asimismo, el diálogo técnico comporta otra problemática consistente en el acceso del comprador público a la información confidencial de los licitadores, a la que asimismo aludiremos más adelante. Puesto que no existe solución actual al problema planteado por el adjudicador, el diálogo técnico entre las partes es más que necesario debiendo estar limitado por la confidencialidad y el secreto que guarda toda información empresarial relacionada con proyectos de $\mathrm{I}+\mathrm{D}+\mathrm{i}$.

Finalmente, nos encontramos con la condición esencial de la CPP relacionada con el reparto de riesgos y beneficios derivados del proceso de $I+D+i$ y la modulación del riesgo y ventura del empresario que ello supone. En un sistema donde el empresario debe correr con todos los riesgos del contrato el régimen compartido entre adjudicador y adjudicatario de las cargas y los beneficios derivados de la contratación de innovación puede interpretarse como uno de los síntomas del necesario cambio de mentalidad en materia de contratación pública.

$\mathrm{Al}$ no existir reglas administrativas que prevean tal reparto, la Administración Pública tendrá que acordar con la empresa licitadora los límites de sus actuaciones en proporción a su participación en el proyecto. De esta forma, los resultados de la CPP no quedan al arbitrio del comprador público, ni del contratista, ambos tendrán que soportar las cargas, esto es, los gastos previstos e imprevistos en los que incurra el proyecto de I+D+i o la generación de un prototipo de producto o servicio, y disfrutar conjuntamente de los resultados, sin que corresponda a ninguno la plena disposición sobre la solución innovadora.

La alteración del principio clásico de riesgo y ventura del contratista, la gestión del riesgo en los proyectos innovadores, la participación en los beneficios y su relación con la retribución del contrato de I+D, la propiedad del bien innovador y su explotación o la confidencialidad son, entre otras, las consideraciones jurídico-administrativas más relevantes en esta materia.

\subsection{La compra pública de tecnología} innovadora. Marco jurídico y procedimental La CPTI que tiene por fin la adquisición y el desarrollo de bienes o servicios tecnológicos, nuevos o mejorados, que no han alcanzado la fase comercial, es decir, que aún no han llegado al mercado o no están disponibles para su distribución a gran escala, pero en los que el grado de innovación ya tiene un grado de madurez considerable. 
La CPTI queda incluida en el ámbito de aplicación de la normativa sobre contratación pública en la forma de contratos de obras, servicios o suministros de los artículos 12 y siguientes de la LCSP.

Esta modalidad de CPI prescinde del proceso previo de I+D+i en fase de creación o diseño de un prototipo inexistente, y se centra en el desarrollo de una idea que necesita adaptación y en la comercialización. Así, pues, la CPTI no parte de la nada, sino de la existencia de un modelo o prototipo que requiere el desarrollo de tecnología nueva o mejorada para cumplir con las exigencias del comprador público.

Dependiendo de las prescripciones propias de cada producto o servicio, la CPTI podrá articularse por los procedimientos de contratación ordinarios (abierto o restringido) y especiales (licitación con negociación, diálogo competitivo y asociación para la innovación). No obstante, las Guías y orientaciones elaboradas por la UE y por las Administraciones españolas recomiendan vivamente en estos casos la elección de un procedimiento en el que las partes contratantes estén en permanente contacto y quepa la negociación, pues los procedimientos con margen de negociación permiten una mayor flexibilidad a la hora de tratar las cuatro premisas básicas de la CPTI:

a) La inexistencia de bienes o servicios específicos que satisfagan las pretensiones de compra de la Administración.

b) El necesario desarrollo tecnológico del prototipo a partir del cual se obtendrá el bien o servicio pretendido en un tiempo razonable.

c) La inevitable espera del comprador público a causa del proceso tecnológico.

d) La indeterminación inicial del precio y el plazo por el que se conseguirá el resultado final.

A partir de estas premisas, los procedimientos con fases negociadas son los más ordinarios y adecuados a las exigencias de la CPTI.

El primero de ellos sería la licitación con negociación prevista en los artículos 166 a 171 de la LCSP, teniendo por objeto contratos de obras, servicios o suministros que necesitan de un desarrollo tecnológico. En este procedimiento, y a partir de la fijación de las características del bien o servicio objeto, se abre una fase de selección con al menos tres licitadores, celebrando rondas de ofertas y negociaciones sucesivas sobre múltiples los aspectos negociables que se definan para cada supuesto (prescripciones técnicas, precio, plazo) y fijando la fecha para la presentación de las ofertas finales.
Otro procedimiento posible para contratar CPTI es el diálogo competitivo, regulado en los artículos 172 a 176 de la LCSP. El diálogo competitivo ofrece a las partes contratantes una mayor flexibilidad que la licitación con negociación al no tener que ceñirse a prescripciones únicas prefijadas, sino que cada oferta se presenta en base a la solución propuesta por cada licitador. Ante proyectos cuyas prescripciones son imposibles de definir de antemano, el diálogo competitivo permite conocer la experiencia previa de las empresas en relación a lo que se pretende contratar ${ }^{(16)}$.

Al igual que en el procedimiento con negociación, el diálogo competitivo se iniciará con la invitación de un mínimo de tres licitadores. Durante el diálogo las propuestas iniciales se irán perfilando hasta acabar determinando las prescripciones técnicas, los criterios de selección y el plazo de duración estimado en un único documento que se pondrá a disposición de los interesados. En virtud de los términos acordados en el diálogo conforme al artículo 172 de la LCSP, los licitadores presentarán sus ofertas finales para la posterior selección de la empresa adjudicataria.

Pero la LCSP, acogiendo las previsiones de la Directiva, diseña un procedimiento específico para la CPI llamado de "Asociación para la innovación" (artículos 177 a 182 de la LCSP). Se trata de un procedimiento complejo, aplicable tanto a los procedimientos de CPP como de CPTI, de escasa aplicación a día de hoy, al que aludiremos específicamente al tratar las especialidades procedimentales de la CPI.

En todo caso, en función de la capacidad descriptiva del bien o servicio pretendido por el órgano de contratación habrá de adoptarse algún procedimiento que acoja la negociación, siendo poco recomendables los procedimientos abiertos ordinarios 0 restringidos por el escaso margen que ofrecen a las diversas opciones y propuestas de desarrollo de la innovación por los licitadores.

(16) Véase en Fundación Cotec para la Innovación Tecnológica. (2011). La compra pública de tecnología innovadora en biotecnología. Libro blanco. Informes sobre el sistema español de innovación. Cotec. 


\section{Aspectos de la CPI que requieren un tratamiento jurídico específico respecto de las reglas comunes de la contratación pública}

\author{
5.1. Singularidades de la preparación y adjudicación del \\ contrato
}

5.1.1. Preparación del contrato: mapas de demanda temprana, consultas preliminares al mercado, demanda agregada y gestión de ofertas no solicitadas

En los procedimientos de CPI es fundamental el desarrollo de una fase previa o preliminar que antecede a la fase legalmente prevista de preparación de los contratos. La planificación supone un mandato del legislador a los órganos de contratación ${ }^{(17)}$. Si esta labor de planificación es necesaria y obligatoria en las licitaciones ordinarias, en las licitaciones complejas, como las de CPI, resulta fundamental para delimitar la necesidad a la que atiende el contrato y si para satisfacerla existe una solución disponible en el mercado y cuál es su grado de maduración tecnológica. De hecho, este análisis preliminar del mercado marcará si el contrato de $\mathrm{CPI}$ será un $\mathrm{CPP}$ o una CPTI.

En este contexto de explotación tecnológica y de planificación del contrato de CPI resulta especialmente recomendable explorar escenarios de demanda agregada, entendida en este caso como la búsqueda activa de otras Administraciones o entes del sector público que compartan la necesidad plateada y se muestren potencialmente interesados en explorar soluciones a través de la CPI. Esa exploración de la demanda agregada a escala internacional en el ámbito de la Unión Europea está fuertemente incentivada con múltiples iniciativas y dotación de fondos específicos por parte de la Comisión Europea.

Las cuestiones nucleares a dilucidar en sede de preparación del contrato (si existe solución disponible según el estado de la técnica y grado de adecuación o desarrollo de la misma) se sitúan fuera del ámbito interno de la Administración y requieren de acciones de indagación y averiguación que orienten la toma de decisión. Para ello la Administración deberá entrar en contacto con el mercado mediante un contacto previo y directo con los potenciales licitadores. Una participación anticipada de los potenciales adjudicatarios que hasta la aparición de la LCSP de 2017, el legislador contemplaba con recelo, pues podía implicar una vulneración del principio de igualdad entre los licitadores; pero que puede y debe convertirse en una práctica habitual en las licitaciones, muy especialmente en las licitaciones de CPI.
Entre las técnicas de análisis de mercado, las más destacadas y novedosas son las denominadas "consultas preliminares al mercado", profusamente reguladas en el artículo 115 de la LCSP. La figura se regula dentro de la sección $1^{\text {a }}$ del Capítulo I del Título I en la regulación de la preparación del contrato. Por tanto, de un lado, no es una práctica previa sino que forma parte del procedimiento administrativo especial que en definitiva es una licitación; y, de otro lado, es un trámite aplicable a licitaciones que no suponen una CPI, si bien está especialmente indicado en éstas.

Como contrapeso del potencial peligro de parcialidad o tratamiento no igualitario que pudiera implicar el contacto previo con los licitadores, el legislador ha potenciado dos principios fundamentales con la imposición de medidas concretas: publicidad y transparencia. Y, así, el artículo 115 de la Ley de Contratos del Sector Público (LCSP) dispone que:

Antes de iniciarse la consulta, el órgano de contratación publicará en el perfil de contratante ubicado en la Plataforma de contratación del Sector Público o servicio de información equivalente a nivel autonómico, el objeto de la misma, cuando se iniciara esta y las denominaciones de los terceros que vayan a participar en la consulta, a efectos de que puedan tener acceso y posibilidad de realizar aportaciones todos los posibles interesados. Asimismo en el perfil del contratante se publicarán las razones que motiven la elección de los asesores externos que resulten seleccionados.

Cuando el órgano de contratación haya realizado las consultas a que se refiere el presente artículo, hará constar en un informe las actuaciones realizadas. En el informe se relacionarán los estudios realizados y sus autores, las entidades consultadas, las cuestiones que se les han formulado y las respuestas a las mismas. Este informe estará motivado, formará parte del expediente de contratación, y estará sujeto a las mismas obligaciones de publicidad que los pliegos de condiciones, publicándose en todo caso en el perfil del contratante del órgano de contratación.

(17) En este sentido, el artículo 28.4 de la LCSP establece que: "Las entidades del sector público programarán la actividad de contratación pública, que desarrollarán en un ejercicio presupuestario o períodos plurianuales y darán a conocer su plan de contratación anticipadamente mediante un anuncio de información previa previsto en el artículo 134 que al menos recoja aquellos contratos que quedarán sujetos a una regulación armonizada". 
Junto a ello se prevé una regla específica de compatibilidad que pretende incentivar la participación de los empresarios en estas consultas, de forma que "la participación en la consulta no impide la posterior intervención en el procedimiento de contratación que en su caso se tramite" (artículo 115 LCSP).

En realidad, la LCSP permite un modelo abierto para el desarrollo de consultas previas a la adjudicación con la salvedad o prevención de que se produzca una participación que constituya un riesgo para la libre competencia y la igualdad de trato. La LCSP solo prevé dos restricciones a la participación de las empresas en las consultas preliminares. Una restricción directa consistente en que la intervención de la entidad en la delimitación preliminar del objeto del contrato no puede ser valorada como un aspecto positivo o preferente con respecto al resto de licitadores. Y una restricción indirecta relativa a la posibilidad de que la activa participación de la empresa en la consulta haya supuesto la concreción de unas características y prescripciones que únicamente puedan ser desarrolladas por la misma, es decir, que el participante se haya "apropiado" del objeto del contrato de tal modo que lo haya diseñado en atención a sus propias capacidades En definitiva, el comprador público tiene que evitar que las actuaciones previas con los agentes del mercado se traduzcan en ventajas desleales y falseamientos de la competencia.

Respecto a los métodos a seguir por el comprador público para la realización de estas consultas, el Dictamen del Consejo de Estado, Núm. 1116/2015, de 10 de marzo de 2016, impone la eficiencia, la innovación, la alta tecnología y la participación empresarial como los valores que deben regir estas actuaciones previas ${ }^{(18)}$.

Velando por estos principios, las consultas preliminares del mercado pueden comprender tres fases destinadas a estimular el mercado y definir adecuadamente el objeto de la CPI, aunque lo cierto es que la LCSP en ningún caso regula la forma en que deben materializarse estas consultas por lo que rige en todo caso la libertad de elección a la Administración sobre la forma de proceder.

A la primera fase nos hemos referido ya al determinar el proceso evaluativo de las necesidades de compra, que conlleva determinar con certeza la necesidad de compra del contratante identificando el ámbito objetivo y subjetivo de la consulta, es decir, las innovaciones potenciales que pueden satisfacer la necesidad y las empresas destinatarias con concreción del sector de actividad. El órgano de contratación tendrá que someterse a un examen interno en el que se describan las ventajas e inconvenientes del proceso de I+D+i y se evalúe la capacidad de la Administración para responder a la necesidad por medios propios así como para definir los bienes o servicios pretendidos. En esta fase de planificación, el ente adjudicador tendrá que elegir la información que va a ofrecer a las empresas. Esta información no sólo debe tratar de la necesidad cuya solución requiere de $\mathrm{I}+\mathrm{D}+\mathrm{i}$, sino que también tendrá que contener el plazo de celebración de la consulta, el precio estimado del contrato y el procedimiento de contratación.

La segunda fase estará protagonizada por el formato de la consulta. En este punto, es preciso recordar que el fin de la consulta preliminar es facilitar un primer contacto entre la Administración y el mercado, Io que resulta imprescindible en materia de CPI. Por tanto, el comprador público debe adoptar el medio idóneo para la celebración de la consulta, pudiendo optar, acumulativa o alternativamente, por anuncios de información previa, encuestas, cuestionarios de mercado, entrevistas, seminarios, conferencias, jornadas, ferias industriales, webinars, etc.

Entre los múltiples formatos, destacamos el encuentro con el mercado o meet the market event (MTM) por ser, a nuestro parecer, el más apropiado para la CPI al permitir una mayor interacción entre la autoridad contratante y las empresas. Para que el MTM se celebre con éxito es de vital importancia la elaboración de un mapa de demanda temprana en el que se determinen los objetivos y requisitos de la consulta junto con la disponibilidad presupuestaria(19). La publicación de este mapa a tiempo puede reducir los riesgos y mejorar la planificación

(18) Las consultas preliminares son una figura contemplada por las normas jurídicas europeas, que preconizan su establecimiento con carácter general en el ámbito de las relaciones contractuales públicas y privadas como método adecuado para favorecer la eficiencia económica. Así, se contempla en el artículo 2.302 del Proyecto de Código Contratual Privado Europeo, en el Plan de Acción sobre un derecho europeo de contratos más coherentes, hecho por la Comisión Europea en enero de 2003, y en el Draft Common Frame of Reference, de 2008. Constituyen, por otra parte, un instrumento adecuado para satisfacer las necesidades perseguidas con los contratos y la idoneidad de sus objetos y contenidos deben determinarse con exactitud, velándose en todo caso por la eficiencia, valorando la innovación y la incorporación de la alta tecnología y promoviendo la participación de las empresas.

(19) Véase en Peiró, A. I. (2016) Las consultas preliminares al mercado y su funcionamiento práctico. Experiencias sobre cómo llevar a cabo un Meet the Market Event. Observatorio de contratación pública. 
de la CPI de forma muy considerable. Agregando la demanda temprana, el comprador público orienta la innovación de las empresas hacia el problema en cuestión.

En lo relativo a la forma de organizar el MTM, puede desarrollarse en una única discusión plenaria en la que el ente adjudicador exponga a modo de conferencia su necesidad y posteriormente, se abra un coloquio entre los asistentes. $\mathrm{O}$ bien, ante un número elevado de participantes, se podrán organizar mesas de debate tras un breve planteamiento de la situación.

La tercera parte de la consulta consistirá en dotar a la misma de la difusión suficiente, teniendo el gestor público que hacer uso de todos los medios a su alcance para hacer llegar al sector privado la información y la documentación de la consulta. Una vez difundida la información, se recomienda la creación de un archivo y la realización de un seguimiento sobre las empresas que hayan mostrado su interés en contratar durante la celebración la consulta.

En materia de innovación es posible que el estímulo de solucionar los problemas de la Administración con ideas novedosas provenga del mismo mercado a través de propuestas u ofertas no solicitadas. Con estas propuestas las empresas se dirigen expresamente al órgano de contratación proponiéndole soluciones innovadoras a necesidades, presentes o futuras, de un determinado bien o servicio que el proponente tiene capacidad de desarrollar.

La gestión de estas ofertas no es fácil por cuanto que el comprador público tiene que detectar si la pretensión del ofertante consiste en crear una necesidad, y así obtener financiación, o en caso contrario, la oferta responde efectivamente a la solución de un problema.

Para que la Administración reciba estas ofertas, que en algunas ocasiones pueden ser calificadas de interés y en consecuencia, la causa de un procedimiento de contratación, la Junta Consultiva de Contratación Administrativa de Cataluña propuso una interesante medida que nos parece generalizable: la creación de un buzón de innovación al que los agentes privados podrán enviar ideas innovadoras aplicables a los ámbitos de actuación del sector público.

En definitiva, a los efectos de la CPI, las consultas preliminares permiten comprobar la existencia de soluciones innovadoras en el mercado o/y el grado de adaptación e innovación que las mismas requerirían para cubrir las necesidades públicas objeto del contrato. En tal supuesto, si la tecnología no existe hasta el momento pero su desarrollo es factible a través de un proceso de I+D+i, la consulta determinará la elección de la CPP, mientras que si la tecnología necesaria no está disponible pero existen modelos o prototipos con los que se puede obtener en un periodo de tiempo estimado, la actuación previa conducirá a la CPTI.
En sede de preparación del contrato, la elaboración y publicación de mapas de demanda temprana por parte de la administración promotora constituye otra de las técnicas para la planificación de las licitaciones CPI que se situaría en el tiempo con carácter previo a las consultas preliminares al mercado. Se trata de una técnica unilateral pues se inicia y desarrolla en el ámbito de la Administración, una iniciativa con una finalidad meramente informativa que no pretende ninguna respuesta expresa y a corto plazo por parte del mercado.

El mapa de demanda temprana permite anticipar al mercado los planes de contratación previstos por parte de la Administración. En cualquier tipo de compra de productos y servicios, la demanda temprana a los proveedores supone un gran beneficio tanto para el sector industrial, al permitirles reducir los riesgos y mejorar la planificación de las inversiones a realizar, llevar a cabo alianzas o uniones temporales con otras empresas para presentarse a la licitación conocida con antelación; como para los propios clientes, al poder ver reducidos los tiempos de ejecución de las soluciones innovadoras existentes en el mercado.

Normalmente se utiliza está técnica asociada al ámbito de la CPI, en el que el mapa de demanda temprana es un listado de necesidades identificadas en nuestro entorno sin solución en el mercado que son susceptibles de proyecto $\mathrm{CPI}$, ya que reúnen los requisitos, técnicos económicos, de financiación y de impacto.

\subsubsection{Especialidades de los pliegos de CPI} En relación a los Pliegos, la mayor singularidad del de prescripciones técnicas es que normalmente recurrirá a la formulación de prescripciones funcionales o de rendimiento que, no obstante, han de ser lo suficientemente precisos para permitir a los licitadores determinar el objeto del contrato y al órgano de contratación adjudicar el mismo (artículo 126 LCSP).

En las prescripciones administrativas, la mayor dificultad la plantea en estos casos la delimitación del objeto del contrato, cuyo grado de incertidumbre derivado de la 
innovación que se pretende explica la previsión del artículo 99.1 de la LCSP, que establece para estos casos que el mismo (aunque "deberá ser determinado", como en el resto de contratos):

Se podrá definir en atención a las necesidades o funcionalidades concretas que se pretenden satisfacer, sin cerrar el objeto del contrato a una solución única. En especial, se definirán de este modo en aquellos contratos en los que se estime que pueden incorporarse innovaciones tecnológicas, sociales o ambientales que mejoren la eficiencia y sostenibilidad de los bienes, obras o servicios que se contraten.

Otro de los aspectos que obligatoriamente debe recoger el pliego son los criterios de solvencia técnica y económica. En los procesos de $\mathrm{CPI}$ se ha de velar por mantener el equilibrio entre la exigencia de unos requisitos de solvencia que permitan la participación de las empresas experimentadas y con capacidad innovadora que verdaderamente puedan aportar soluciones, pero sin que tales exigencias supongan un obstáculo a la PYMES o micro PYMES con alta capacidad innovadora (start up), pero con escaso bagaje profesional y generalmente poca experiencia como empresa.

Respecto de los criterios de adjudicación, la LCSP exige que estén vinculados con el objeto del contrato, por lo que en los procedimientos CPI en los que el objeto del contrato no está del todo definido se hace especialmente complejo establecer con exactitud dichos criterios. Por ello, en estas licitaciones será generalmente aplicable la regla establecida en el artículo 145.3, que contiene los supuestos en los que resulta obligatoria la aplicación de más de un criterio de adjudicación en los que hasta tres de estos supuestos concuerdan con los elementos que se pueden encajar perfectamente en licitaciones $\mathrm{CPI}$ :

a) Aquellos cuyos proyectos o presupuestos no hayan podido ser establecidos previamente y deban ser presentados por los candidatos o licitadores.

b) Cuando el órgano de contratación considere que la definición de la prestación es susceptible de ser mejorada por otras soluciones técnicas o por reducciones en su plazo de ejecución.

c) Aquellos que requieran el empleo de tecnología especialmente avanzada o cuya ejecución sea particularmente compleja.
Lo normal es entender que la limitación afecta a los criterios de adjudicación que se han de tener en cuenta para seleccionar la oferta con la mejor relación calidad - precio (artículo 145.1 LCSP), que en ningún caso se pueden eliminar ni sustituir por otras ni variar su ponderación a lo largo del proceso negociador, entendemos que sí debe estar permitido negociar sobre los criterios de adjudicación. Una cosa es negociar sobre el precio del contrato y otra cosa es negociar si el precio del contrato se elimina como criterio de adjudicación o se altera su ponderación o la puntuación asignada en la valoración de las ofertas. Entendemos que lo primero está permitido y que lo segundo es lo que parece razonable que se prohíba, pues de ser así supondría una alteración de las reglas del juego y una desviación de la preceptiva vinculación de la administración a lo dispuesto en el pliego. De no ser esta la interpretación del alcance del referido precepto, la capacidad y margen de negociación quedarían prácticamente anulados, eliminado el elemento nuclear de este procedimiento que es la negociación.

Otra peculiaridad muy relevante de la CPI es la posibilidad de establecer el valor estimado del contrato mediante el recurso a precios provisionales, lo que expresamente prevé el artículo 102 de la $\operatorname{LCSP}^{(20)}$, cuya fijación debería acompañarse de obligaciones del adjudicatario relativas al régimen de auditoría de costes y precios, consistente es un examen crítico y sistemático de los estados de costes del contrato; así como de una metodología de cálculo del beneficio, que los contratistas deberían someter al auditor para determinar el precio definitivo de los contratos adjudicados con precios provisionales en procedimientos negociados, diálogo

(20) Excepcionalmente pueden celebrarse contratos con precios provisionales cuando, tras la tramitación de un procedimiento negociado, de un diálogo competitivo, o de un procedimiento de asociación para la innovación, se ponga de manifiesto que la ejecución del contrato debe comenzar antes de que la determinación del precio sea posible por la complejidad de las prestaciones o la necesidad de utilizar una técnica nueva, o que no existe información sobre los costes de prestaciones análogas y sobre los elementos técnicos o contables que permitan negociar con precisión un precio cierto.

En los contratos celebrados con precios provisionales el precio se determinará, dentro de los límites fijados para el precio máximo, en función de los costes en que realmente incurra el contratista y del beneficio que se haya acordado, para lo que, en todo caso, se detallarán en el contrato los siguientes extremos: a) El procedimiento para determinar el precio definitivo, con referencia a los costes efectivos y a la fórmula de cálculo del beneficio; b) Las reglas contables que el adjudicatario deberá aplicar para determinar el coste de las prestaciones; c) Los controles documentales y sobre el proceso de producción que el adjudicador podrá efectuar sobre los elementos técnicos y contables del coste de producción. 
competitivo y asociaciones para la innovación, contribuyendo a conseguir racionalidad y transparencia de las compras y la gestión del gasto público(21).

\subsubsection{En especial, el procedimiento de Asociación para la Innovación}

Como ha quedado dicho, la CPI no es un procedimiento de licitación. En principio cualquiera de los procedimientos regulados en la Ley puede ser utilizado para adjudicar un contrato de innovación, aunque por las razones advertidas, nos hemos decantado en estos casos por la preferencia por los procedimientos que incluyan negociación con los licitadores. Como antes apuntábamos, la Directiva y la LCSP prevén al efecto un procedimiento específico para la CPI: la asociación para la innovación, aun escasamente utilizado, probablemente por su gran complejidad.

Es de interés lo que señala el considerando 49 de la Directiva 2014/24/UE a propósito de este procedimiento específico:

(...) debe permitir a los poderes adjudicadores establecer una asociación para la innovación a largo plazo con vistas al desarrollo y la ulterior adquisición de nuevos productos, servicios u obras innovadores, siempre que estos se ajusten a un nivel acordado de prestaciones y de costes, sin necesidad de recurrir a un procedimiento de contratación independiente para la adquisición. La asociación para la innovación debe basarse en la normativa aplicable al procedimiento de licitación con negociación y los contratos deben adjudicarse únicamente basándose en la mejor relación calidad-precio, que es la más indicada para comparar las ofertas de soluciones innovadoras. En lo que respecta tanto a los proyectos de gran envergadura como a los proyectos innovadores de menor calado, la asociación para la innovación debe estar estructurada de tal manera que genere el necesario "tirón comercial", incentivando el desarrollo de soluciones innovadoras sin cerrar el mercado.

Las ideas-fuerza que se extraen de las pretensiones de las Directivas son, de un lado la necesidad de que se delimite en la documentación preparatoria y que rija la licitación (con negociación) un nivel mínimo de prestaciones y máximo de costes; de otro, la necesidad de ponderar únicamente como criterio de valoración la mejor calidad precio, prescindiéndose, por tanto, por supuesto de solo el precio, pero también de otros elementos como los criterios medioambientales o sociales. Además, dado que se trata de buscar nuevos productos o servicios, lo que implica cierta inversión por parte de los operadores económicos, el proceso debe incentivar o facilitar el interés de éstos, vía abono de parte de los costes incurridos en caso de fracaso o mediante la salvaguarda de los derechos de la propiedad intelectual o industrial, por ejemplo, pero sin cerrar el mercado de cara al futuro.
Así, en el considerando 4 de la Directiva 2014/24/UE del Parlamento Europeo y el Consejo, se añade que "Los poderes adjudicadores, por tanto, no deben utilizar las asociaciones para la innovación de tal manera que la competencia se vea obstaculizada, restringida o falseada". Es por eso que, para evitar esos efectos, se intenta fomentar el establecimiento de asociaciones para la innovación con varios socios.

Aunque el procedimiento, que tiene carácter excepcional, implica -como es lógico- ciertas restricciones de la normal competencia (precisamente porque se trata de fomentar productos, bienes o servicios no existentes), debiendo asegurarse el órgano de contratación, a fin de evitar la pérdida del tiempo y de dinero, que los candidatos que participen y con los que se negocie realmente estén en condiciones de poder desarrollar posteriormente los prototipos resultantes.

Así el considerando 84 de la Directiva cuando explica las medidas de las Directivas de favorecimiento de pequeñas y medianas empresas y la necesidad de reducir el exceso de cargas administrativas que conlleva la obligación de presentar un número sustancial de certificados u otros documentos relacionados con los criterios de exclusión y de selección (para lo que se crea el documento europeo único de contratación), explica que para las asociaciones para la innovación los poderes adjudicadores pueden aprovechar la posibilidad de limitar el número de candidatos invitados a presentar una oferta. Para el legislador europeo "Exigir la presentación de la documentación complementaria en el momento de seleccionar los candidatos que vayan a ser invitados podría estar justificado para evitar que los poderes adjudicadores inviten a candidatos que se muestren incapaces de presentar la documentación complementaria en la fase de adjudicación, privando de la participación a otros candidatos cualificados" (considerando 68 de la Directiva 2014/14/UE).

El artículo 31 de la Directiva se ocupa de regular este singular procedimiento de "Asociación para la innovación". El precepto

(21) Véase en Gómez, J.C. (2018). La determinación del precio de los contratos públicos con base en el coste. Wolters Kluwer. 
parte de una convocatoria de licitación que tendrá en cuenta elementos cualitativos (no sólo el precio), en la que se filtra previamente a los candidatos, aunque se permita que cualquier operador pueda presentar una solicitud de participación. Así, por exigencia de la propia Directiva, en los pliegos debe determinarse:

a) La necesidad de un producto, servicio u obra innovadores (que no estén disponibles en el mercado). Especificándose de forma precisa la naturaleza y ámbito de la solución requerida.

b) Los requisitos mínimos que han de cumplir los licitadores, debiendo tratarse de criterios relativos a la capacidad de los candidatos en los ámbitos de la investigación y del desarrollo, así como de la elaboración y aplicación de soluciones innovadoras. Es decir, los licitadores deben tener experiencia en la innovación.

c) Posibilidad y condiciones para rescindir la asociación para la innovación en cada fase o, si hubiera varios socios, reducir su número mediante la rescisión de los contratos individuales.

d) El criterio de selección, que será la mejor calidad-precio.

e) Las disposiciones aplicables a los derechos de propiedad intelectual e industrial.

En cuanto al procedimiento, se inicia con la criba de las solicitudes de participación. Una vez seleccionados los candidatos participantes, que podrán ser varios que efectúen por separados actividades de investigación y desarrollo, la asociación para la innovación se estructurará en fases sucesivas siguiendo la secuencia de las etapas del proceso de investigación e innovación, que partirán desde la creación de conocimiento hasta su aplicación para convertirlo en un producto o un servicio que incorpore nuevas ventajas para el mercado, o a la mejora de los procesos productivos, y a facilitar la introducción del producto o servicio resultante en el mercado, pudiendo llegar en el mejor de los casos hasta la fabricación de los productos, la prestación de los servicios o la realización de las obras, pero -para el caso de que así no ocurriese- se establecerán unos objetivos intermedios que deberán alcanzar los socios y proveerá el pago de la retribución en plazos adecuados. Para evitar un incremento absurdo de costes, en las condiciones fijadas en los pliegos, llegados a cada fase, podrá rescindirse toda la operación o reducirse el número de candidatos que continúen en la siguiente fase.

Por exigencias de la Directiva, el procedimiento se inspirará en la licitación con negociación, por ello -con pleno respeto al principio de igualdad de trato y confidencialidad- los licitadores podrán mejorar el contenido de las ofertas iniciales y todas las ofertas ulteriores presentadas por estos, excepto la oferta definitiva. Igualmente, podrán articularse fases sucesivas o eliminatorias.

Pero, más allá de las previsiones generales sobre negociación y selección, en las que se contempla que los operadores económicos a los que invite el poder adjudicador tras evaluar la información solicitada serán los que presenten los proyectos de investigación e innovación, el artículo 31 no determina de forma clara y ordenada cómo ha de articularse o materializarse el procedimiento.

Finalmente, el artículo 31 de la Directiva establece que el poder adjudicador velará por que la estructura de la asociación $y$, en particular, la duración y el valor de las diferentes fases reflejen el grado de innovación de la solución propuesta y la secuencia de las actividades de investigación y de innovación necesarias para el desarrollo de una solución innovadora aún no disponible en el mercado.

\subsection{El problema de la confidencialidad en torno a la I+D+i}

El principio de confidencialidad de la contratación pública y su confrontación con la publicidad y la transparencia del procedimiento ha sido un tema más controvertido en el ámbito del Derecho de la contratación pública, especialmente a partir de la entrada en vigor de la Ley 19/2013, de 9 de diciembre, de transparencia, acceso a la información pública y buen gobierno $(\mathrm{LT})^{(22)}$. Esta colisión de principios tiene una especial relevancia en la $\mathrm{CPI}$, debido al objeto característico de estos contratos.

Para garantizar el equilibrio entre la confidencialidad de los expedientes y el derecho de acceso a los mismos por cualquier persona, física o jurídica, que tenga interés legítimo en ello, es preciso partir de la debida confianza mutua entre el órgano contratante y los interesados. Es conocida la doctrina sentada por el Tribunal de Justicia de la Unión Europea en su Sentencia, de 29 de enero de 2013, asunto T-339/10, Cosepuri/EFSA, entre otras, donde afirma que:

(22) Véase, con carácter general, en Razquin, M. (2013). La confidencialidad de los datos empresariales en poder de las Administraciones Públicas (Unión Europea y España). lustel. 
Además, tanto por su naturaleza como conforme al sistema de la normativa de la Unión en la materia, los procedimientos de adjudicación de contratos públicos se basan en una relación de confianza entre las entidades adjudicadoras y los operadores económicos que participan en ellos. Éstos han de poder comunicar a tales entidades adjudicadoras cualquier información útil en el marco del procedimiento de adjudicación, sin miedo a que éstas comuniquen a terceros datos cuya divulgación pueda perjudicar a dichos operadores.

Efectivamente, los licitadores tienen que estar tutelados por la confianza recíproca de forma que se les garantice que la información suministrada al poder adjudicador no será transmitida a terceros, ni al público en general, sin su consentimiento expreso.

En el plano interno, la LCSP prevé un tratamiento igualitario, no discriminatorio y ajustado a los principios de transparencia y proporcionalidad permitiendo a las empresas licitadoras el acceso a los documentos obrantes en el expediente de contratación con el límite del respeto a la confidencialidad (artículo 132).

Asimismo, la legislación de Transparencia exige a la Administración Pública el efectivo cumplimiento de la transparencia a la hora de informar sobre sus actividades. Parece que la regla general radica en facilitar la máxima información a los licitadores siempre y cuando se mantengan incólumes los límites de la confidencialidad regulada en el artículo 133 de la LCSP (artículo 21 de la Directiva 2014/24/UE). El citado precepto impone que la protección de la información confidencial no sea absoluta de forma que admita una declaración genérica de confidencialidad al arbitrio del licitador, pues ello dejaría sin contenido los principios de publicidad y transparencia.

Los Tribunales Administrativos especiales en materia de contratación se han pronunciado limitando las pretensiones de confidencialidad de las empresas. Concretamente, el Tribunal Administrativo Central de Recursos Contractuales en su Resolución Núm. 62/2012, de 29 de febrero, sostuvo que:

En el caso que nos ocupa, la adjudicataria del contrato, ha señalado confidencial la totalidad de la documentación que compone su proposición (sobre1 de documentación administrativa; sobre 2 de solvencia técnica, económica y financiera; sobre 3 de documentación técnica, y; sobre 4 de proposición económica) sin referirse por tanto a los aspectos concretos de su oferta que debieran ser mantenidos bajo secreto, pues, según parece, considera que toda su documentación tiene el carácter de secreta y por tanto confidencial. A estos efectos, este Tribunal entiende que esta obligación de confidencialidad no puede afectar a la totalidad de la oferta realizada por el adjudicatario, habida cuenta de que el propio artículo 124.1 de la LCSP garantiza que este deber de confidencialidad no debe perjudicar el cumplimiento de las obligaciones en materia de publicidad e información que debe darse a candidatos y licitadores, obligaciones entre las que se encuentran incluidas las enumeradas en el artículo 135.4 de la propia LCSP (artículo 151.4 TRLCSP).
De ello puede deducirse una regla general prohibitiva de las declaraciones de confidencialidad que comprendan la totalidad de la documentación, ya que suponen una contradicción evidente con la publicidad y la transparencia que deben regir en todo procedimiento de contratación y con las que el principio de confidencialidad ha de contrastarse en términos de proporcionalidad.

Por tanto, para realizar una declaración de confidencialidad conforme a los principios de la contratación pública será conveniente conocer qué tipo de información es susceptible de ser calificada como tal. De acuerdo con lo anterior, la Resolución del Tribunal Administrativo de Recursos Contractuales, Núm. 196/2016, de 11 de marzo de 2016, delimita el concepto y los requisitos para que la información sea considerada como confidencial, declarando así que:

En este sentido, cabe recordar que la jurisprudencia ha concretado el concepto de secretos técnicos o comerciales como el conjunto de conocimientos que no son de dominio público y que resultan necesarios para la fabricación o comercialización de productos, la prestación de servicios, y la organización administrativa o financiera de una unidad o dependencia empresarial, y que por ello procura a quien dispone de ellos de una ventaja competitiva en el mercado que se esfuerza en conservar en secreto, evitando su divulgación. La confidencialidad deriva de la posibilidad de que se perjudiquen intereses legítimos o a la competencia leal entre empresas, de modo que, como señala el acuerdo del TACP Madrid 106/2015 los requisitos para calificar de confidencial la documentación presentada por los licitadores son los siguientes:

a) que comporte una ventaja competitiva para la empresa,

b) que se trate de una información verdaderamente reservada, es decir, desconocida por terceros,

c) que represente un valor estratégico para la empresa y pueda afectar a su competencia en el mercado, $y$,

d) que no se produzca una merma en los intereses que se quieren garantizar con los principios de publicidad y de transparencia.

La información podrá estar amparada por el régimen de confidencialidad cuando estando relacionada con un secreto técnico o comercial, ésta suponga una ventaja 
competitiva para el licitador, no esté expuesta al dominio público y disponga de valor estratégico. Y ello siempre que la reserva de tal información no vulnere los principios de publicidad y transparencia.

Esta definición se aproxima mucho a la naturaleza de los bienes y servicios pretendidos por el órgano contratante en los procesos de CPI. Tratando de resolver problemas actuales con soluciones innovadoras cuyo desarrollo requieren de $\mathrm{I}+\mathrm{D}+\mathrm{i}$, las dos modalidades de $\mathrm{CPI}$ precisarán de una documentación que puede ser singularmente valiosa para el mercado en virtud del carácter innovador del objeto del contrato.

Por ello, podemos decir que toda la información relacionada con la investigación tecnológica y el desarrollo experimental (prototipos y modelos industriales, patentes, marcas, diseños, fórmulas y compuestos químicos, know-how, campañas publicitarias estratégicas) requerirá de un alto nivel de confidencialidad pues, en caso de ser reveladas, el empresario corre el riesgo de ver frustradas sus expectativas de negocio.

En orden a evitar la revelación de la información, corresponde al licitador la carga de probar que cierta documentación entra dentro del concepto de secreto técnico o comercial y cumple los requisitos antes expuestos. En apoyo a esta tesis se pronuncia la Resolución del Tribunal Administrativo de Recursos Contractuales, Número 710/2016, de 16 de septiembre, que afirma que:

Si bien la carga de precisar qué elementos de la oferta son confidenciales recae sobre el ofertante, el órgano de contratación -en aras de la transparencia y para evitar la indefensión de otros licitadores interesados- no tiene por qué admitir sin más el ámbito de confidencialidad declarado por el ofertante, sino que debe reducirlo, si el licitador ha extendido la confidencialidad a elementos de su oferta que no deban tener esta cualidad; tanto más cuando en el momento de presentación de la oferta el licitador no hizo declaración de confidencialidad alguna.

Aunque la carga probatoria de la confidencialidad pertenezca al licitador, será la Administración la que tenga la última palabra sobre el carácter de la información debiendo reducir, e incluso denegar, la solicitud en aquellos supuestos en los que la falta de revelación de la documentación lesione la publicidad y la transparencia de la contratación pública.

Finalmente, el gestor público tendrá que realizar una ponderación de los intereses en juego sacrificando en cada caso el derecho de acceso o el interés en la confidencialidad según el carácter de la información y los riesgos que entrañe su revelación.

\subsection{El reparto de beneficios y riesgos en los contratos de CPI}

Dada la complejidad del objeto de los contratos de CPI y la indeterminación inicial del bien o servicio, la modulación convencional por las partes en la regulación del riesgo y ventura del empresario resulta esencial en este tipo de contratos. Poco éxito y capacidad de incentivación tendrían estas políticas de fomento de la innovación si se le impone exclusivamente a la empresa adjudicataria la asunción de todos los riesgos derivados de $I+D+i$.

Frente al reparto de riesgos y beneficios entre comprador público y agente del mercado se erige uno de los principios más característicos del contrato administrativo consistente en que los contratos públicos se ejecutan a riesgo y ventura de la empresa adjudicataria excluyendo a la Administración de la asunción de cualquier riesgo devenido en la relación contractual, por asumir el contratista una obligación de resultados. En puridad, el sentido del riesgo y ventura de los contratos públicos radica justamente en la exclusión de la fuerza mayor como causa justificante del contratista a diferencia del régimen general de exclusión de responsabilidad de las partes por riesgos imprevistos o inevitables del artículo 1.105 del Código Civil.

Una aplicación estricta del riesgo y ventura conforme al artículo 197 de la LCSP puede suponer un obstáculo al desarrollo de la CPI ("La ejecución del contrato se realizará a riesgo y ventura del contratista, sin perjuicio de lo establecido para el contrato de obras en el artículo 239"). Pese a ser la regla general, tanto la normativa como la jurisprudencia han ido introduciendo excepciones principalmente relacionadas con los contratos de concesión. En concreto, las excepciones o modulaciones de riesgo y ventura del empresario encuentran su fundamento en los clásicos supuestos de modificación del objeto del contrato pro el ejercicio del ius variandi de la Administración, que generan compensación al contratista; los supuestos de ruptura sustancial de la economía del contrato por causa imputable a la Administración o como consecuencia del factum principis; así como los supuestos de fuerza mayor o la aparición de circunstancias imprevisibles y externas a la relación contractual cuya aparición traiga consigo la quiebra del equilibrio económico del contrato, de tradicional aplicación al ámbito de las concesiones. 
Pero este marco conceptual clásico puede mostrarse inoperante o insuficiente para la CPI. Ciertamente, la investigación tecnológica y el desarrollo experimental aplicable a las soluciones innovadoras contratadas por la vía de la CPI comportan riesgos imprevisibles que quedan fuera del alcance del contratista y que están en la esencia misma de la innovación, pues la CPI tiene -por definición- un objeto total o parcialmente indeterminado y de incierto cumplimiento, que en el caso de la CPP es tan notable que determina la exclusión de esta modalidad de CPI de la LCSP y la compartición de riesgos entre Administración y contratista.

La mayor o menor indeterminación inicial del objeto, el cual se irá concretando a medida que se vaya desarrollando el proceso de I+D, se traduce en una imprevisibilidad de los riesgos real y ajena al buen o mal hacer de las partes. Los riesgos imprevisibles del contrato serán calificados como tal siempre que adjudicador y adjudicataria hayan actuado de buena fe y se haya aplicado un grado razonable de previsión. Por eso, aquí han de apurarse al máximo las posibilidades de la teoría del riesgo imprevisible, en el entendimiento de que el mantenimiento del equilibrio económico del contrato y la aplicación del riesgo imprevisible en ningún caso puede suponer una cobertura total de los riesgos para el adjudicatario de tal forma que produzca la inversión o completa desaparición del principio de riesgo y ventura propio de la contratación pública.

No obstante, los riesgos de todo proceso creativo de I+D+i tienden a ser imprevisibles y muchas veces ajenos a las partes contratantes. De ahí el interés de acredita en los Pliegos que el objeto y desarrollo del contrato está condicionado a la búsqueda de una solución inexistente y, por otro lado, que la solución innovadora pretendida va a ser desarrollada mediante técnicas aplicativas de I+D+i, que implica siempre una cierta incertidumbre sobre el resultado. Ciertamente, en la CPI la imprevisibilidad de los riesgos puede derivar bien de la propia indeterminación del producto o servicio, bien de la ejecución de los procesos de I+D+i. De hecho, los riesgos derivados de proyectos innovadores suelen ser muy elevados y precisan de una participación conjunta, siendo muy improbable que los resultados sean positivos cuando sólo uno de los inversores se ha hace responsable de todos los costes que entraña la I+D+i.

La compartición de riesgos y la modulación del principio de riesgo y ventura, así como la posible participación de la Administración en los derechos derivados de la generación de un producto o servicio innovador hace que en los CPI cobre especial interés, más allá de la habilitación que puedan contener los Pliegos, el clausulado del contrato que resulta de la adjudicación, de modo que en él pueda plasmarse de modo claro el control del grado de satisfacción -del éxito funcional-, obtenido por un producto o servicio innovador o mejorado, la modulación de los riesgos en razón de los anterior, así como el posible repartos de beneficios Administración/ contratista en proporción al reparto de los riesgos acordado. Lo que se pretende, en suma, es que las partes acuerden un régimen equitativo de los riesgos y los resultados derivados de $1+D+i$ en base al principio de libertad de pactos que actualmente recoge el artículo 34 de la LCSP.

La distribución equitativa de los riesgos y los beneficios de CPI no pretende revestir al adjudicatario de una cobertura total frente a los costes del contrato, sino de mitigar el desequilibrio natural de las prestaciones en la contratación de soluciones innovadoras inexistentes en el mercado.

La imprevisibilidad de la CPI parte de su propio objeto, el cual será desarrollado íntegramente en proyectos de CPP, y partirá de prototipos o modelos ya creados en CPTI, permite afirmar que los riesgos a asumir por las partes serán muy altos. Por ello, la Administración Pública y el sector privado deberán ejecutar los contratos de CPI bajo acuerdos que garanticen el equilibrio de fuerzas de las partes, en los que asuman, individual y proporcionalmente, los costes estimados del contrato y soporten conjuntamente los riesgos imprevisibles derivados del proceso de $1+D+i$ y de la propia naturaleza de la contratación de innovación.

El éxito de la CPI depende en gran parte del reparto de los riesgos, pues ello constituye un incentivo para que las empresas apuesten por la innovación con la garantía de que no estarán solas en el proyecto, sino que contarán con el apoyo del socio más fiable, la Administración Pública. Consecuentemente al régimen compartido de los riesgos, el comprador público y la empresa disfrutarán conjuntamente de los beneficios obtenidos en los proyectos de $\mathrm{CPI}$, sin que la Administración tenga que reservarse para sí los resultados de la I+D+i. Asimismo, tampoco tiene por qué apropiarse exclusivamente al empresario el uso y disfrute del bien o servicio innovador, que en los supuestos de "asociación para la innovación" es dable.

Ciertamente, la CPI constituye una oportunidad para que la autoridad contratante y el empresario se beneficien de los resultados de $\mathrm{I}+\mathrm{D}+\mathrm{i}$, si bien, es necesario prevenir que 
el primero caiga en la tentación de reservarse los derechos de propiedad industrial e intelectual y el segundo perjudique a la Administración en la explotación de tales derechos. No obstante, la práctica habitual en la contratación pública a la hora de regular la propiedad industrial e intelectual choca con lo que venimos diciendo sobre la conveniencia de procurar un reparto equitativo de los beneficios de la CPI, ya que el órgano de contratación tiende a reservarse dicha propiedad con independencia de quién y cómo se haya generado y del uso que el mismo vaya a hacer.

La reserva exclusiva de la propiedad industrial e intelectual por la Administración fue objeto de crítica en el Informe y Conclusiones de la Comisión de expertos del Ministerio de Hacienda para el estudio y diagnóstico de la situación de la contratación pública de 2004 , donde ya se afirmaba que:

La exigencia de los pliegos de que el órgano de contratación adquiera todos los derechos de propiedad intelectual, puede estar ocasionando un coste adicional para el contratista, con su consecuente reflejo en el precio del contrato, además de poder ser un obstáculo a la capacidad de innovación del contratista que se basa en conocimientos adquiridos previamente.

Así pues, se considera recomendable establecer como criterio general que, en aquellos contratos de los que dimanen derechos de propiedad intelectual, el esquema de asignación de aquella sea el establecido en la legislación de la propiedad intelectual. Las alteraciones a dicho principio, derivadas de las posibles necesidades de los órganos de contratación de adquirir dichos derechos, es conveniente que se establezcan de forma diferenciada en los pliegos de cláusulas particulares al objeto de su valoración independiente.

El mencionado Informe recomienda la aplicación de la normativa sobre propiedad industrial e intelectual con un tratamiento diferente y autónomo al resto de aspectos regulados en los pliegos. Junto a ello, detecta un doble inconveniente en la reserva de los derechos a favor del órgano de contratación: el coste adicional y la reducción de la capacidad de innovación del contratista.

Ante tales inconvenientes y con el fin de fomentar la innovación empresarial, la Administración debe propiciar que puedan compartirse los resultados del contrato materializados en los derechos de propiedad industrial e intelectual que dimanan del proceso de desarrollo tecnológico y la innovación experimental. El gestor público compartirá los resultados de I+D+i con las empresas adjudicatarias mediante la publicación, normalización y comercialización del bien o servicio innovador. Asimismo, el poder adjudicador deberá prevenir que la concesión de estos derechos a las empresas no constituya ninguna forma de ventaja injusta, ni tampoco perjudique a los proveedores, especialmente a las $\mathrm{PYME}^{(23)}$.
Respecto al objeto sobre el que recae la propiedad intelectual e industrial, podemos diferencias tres concretos ámbitos en la CPI:

1. Las tecnologías aportadas con carácter previo a la puesta en marcha del proceso de $\mathrm{I}+\mathrm{D}+\mathrm{i}$. Las propiedades que tienen las partes antes de la formalización del contrato reciben la denominación de background y, en principio, no forman parte del objeto del contrato. Ahora bien, si la solución a desarrollar o foreground precisa de la aportación de background será conveniente incluir en el contrato una licencia no exclusiva e ilimitada de éste último que permita a la empresa desarrollar el proceso de I+D sin tener que pedir permiso a la Administración y viceversa.

2. Los bienes o servicios objeto de la contratación y las tecnologías desarrolladas. Como regla general, los derechos de propiedad industrial e intelectual serán retenidos por la empresa, salvo que existan determinadas razones de interés general que lleven al comprador público a conservar tales derechos durante un período de tiempo determinado, como por ejemplo cuando la CPI consista en la contratación de soluciones innovadoras aplicables a la seguridad del Estado.

3. El uso y disfrute de los nuevos bienes o servicios y las tecnologías desarrolladas. Los operadores económicos serán los titulares de los resultados del contrato de $\mathrm{CPI}$ mientras que al órgano de contratación le corresponderá un derecho de uso limitado en el tiempo. El derecho de uso y disfrute de la Administración sobre los bienes, servicios y tecnologías derivados del contrato podrá traducirse en un canon o royalty a cargo del adjudicatario. La cuantificación de dicho canon variará en función de los resultados de explotación obtenidos.

Otra fórmula a considerar puede consistir en una reducción de precios respecto del coste de desarrollo exclusivo que refleje el

(23) Comunicación de la Comisión al Parlamento Europeo, al Consejo, al Comité Económico y Social Europeo y al Comité de las Regiones, "La contratación precomercial: impulsar la innovación para dar a Europa servicios públicos de alta calidad y sostenibles", pp. 7 y ss. 
valor de mercado de los beneficios y los riesgos asumidos por la adjudicataria. En este supuesto, la empresa se compromete a suministrar los bienes o servicios a un precio rebajado como contraprestación a la autoridad adjudicadora por actuar como cliente de lanzamiento.

Igualmente, las partes podrían acordar la inclusión de cláusulas de mejor fortuna a partir de las cuales, el comprador público recibirá en concepto de compensación las plusvalías que se vayan generando por las transmisiones sucesivas a terceros de los derechos de propiedad industrial e intelectual.

Como mecanismo de control, los Pliegos podrán contemplar una cláusula de rescate de los derechos de propiedad industrial e intelectual a favor del órgano contratante en caso de que se verifique que la empresa no ha llevado a cabo ningún tipo de actividad tendente a la explotación comercial. El rescate tendrá efecto una vez haya transcurrido el plazo pactado en el propio pliego, que normalmente suele comprender dos o tres años.

Finalmente, también cabe la posibilidad de que el comprador público reciba la compensación pasando a formar parte del capital social de la empresa adjudicataria según dispone el artículo 56.1 de la Ley de Economía Sostenible. Las partes podrán concertar esta fórmula siempre que se haya contratado con organismos públicos de investigación, universidades públicas, fundaciones del sector público estatal, sociedades mercantiles estatales u otros centros de investigación dependientes de la Administración General del Estado.

\section{Conclusiones}

Los procedimientos de Compra Pública de Innovación (CPI) no siguen las pautas ordinarias de la contratación pública. En estos casos, tanto la preparación y adjudicación del contrato como su ejecución han de adaptarse a una forma de comprar que se basa en unas premisas singulares que en buena medida cuestionan los principios clásicos de la contratación: objeto cierto, precio determinado, inmediatez y corto plazo, riesgo y ventura del empresario; evolucionado hacia modelos en los que prima la negociación con el mercado y el reparto de riegos ante la incertidumbre que inevitablemente conlleva la adquisición de innovación.

Desde la perspectiva del régimen jurídico aplicable al contrato, debe distinguirse entre compra pública pre-comercial (CPP) y compra pública de tecnología innovadora (CPTI). La CPP es un contrato de servicios de $\mathrm{I}+\mathrm{D}+\mathrm{i}$ que requieren un alto desarrollo tecnológico, por lo que el riesgo de la inversión y la incertidumbre sobre el resultado es alto. En este tipo de contratos se comparten habitualmente los riesgos, de modo que el comprador no se reserva la propiedad los resultados y comparte con el contratista las inversiones y los riesgos y beneficios derivados del proceso de creación, desarrollo y ejecución de soluciones inexistentes hasta el momento en el mercado, lo que explica su exclusión de la legislación de contratos públicos, donde este esquema sinalagmático no tiene encaje natural. Frente a ello, la CPTI consiste en la contratación de un bien o servicio innovador, pero cuyo desarrollo y ejecución puede llevarse a cabo en un período de tiempo razonable a partir de modelos o prototipos preexistentes. El objeto de esta compra es la adquisición de tecnología nueva o mejorada que ya ha pasado algún proceso previo de I+D+i. La diferencia entre una y otra modalidad de compra de innovación tiene un tratamiento diferente desde la perspectiva de la aplicación de la legislación de contratos del sector público, por cuanto la primera de las referidas modalidades, la CPP es, en principio, un contrato excluido de la de la Directiva 2014/24/UE y de la LCSP, salvo que los beneficios pertenezcan exclusivamente al poder adjudicador para su utilización en el ejercicio de su propia actividad y, además, el servicio prestado sea remunerado íntegramente por aquel.

No obstante, ambas modalidades de CPI comparten características y elementos comunes, relativos a las fases de preparación, adjudicación y ejecución del contrato.

Entre las actuaciones previas, el órgano de contratación podrá establecer su programa de compras de innovación a partir de "mapas de demanda temprana", realizar consultas preliminares al mercado, organizar el meet the market event a fin de identificar y agregar la demanda, e incluso gestionar ofertas no solicitadas de bienes o servicios desconocidos por la Administración Pública.

Asimismo, una CPI conlleva singularidades de la preparación y adjudicación del contrato y en la elaboración de los Pliegos, las prescripciones técnicas del servicio o producto que se pretende adquirir, que no pueden ser normalizados sino específicos para operación concreta de compra, lo que hace muy aconsejable disponer del auxilio Oficinas técnicas, prescripciones funcionales y determinación abierta del precio a partir de previos provisionales que se van conformando mediante una metodología de open book, que debería venir acompañada de una auditoría específica de costes. 
Por otra parte, todo proyecto que tenga por resultado tecnología nueva o mejorada requiere de un tratamiento anticipado de los derechos de propiedad industrial e intelectual. Por ello, el ente adjudicador y la empresa puede acordarse un régimen de propiedad compartido sobre la tecnología y el bien o servicio resultante.

La participación de empresas en los procedimientos de contratación siempre conlleva el debido respeto a la confidencialidad y secreto de la información empresarial. Lógicamente, este deber de confidencialidad por parte de los contratantes aumenta su nivel de exigencia cuando se trata de proyectos relacionados con nuevas tecnologías e $\mathrm{I}+\mathrm{D}+\mathrm{i}$, de forma que en proyectos de CPI en razón del objeto creativo e innovados del contrato y la participación de una pluralidad de licitadores en el proceso de negociación.

Finalmente, en los contratos de CPI el principio de riesgo y ventura en la ejecución del contrato requiere modulaciones de principio general de imputar todo el riesgo a cuenta exclusiva del empresario que recoge de forma prácticamente incondicionada el artículo 197 de la LCSP. La necesaria interacción entre el órgano de contratación y el empresario contratista a la hora de contratar innovación obliga a una mayor flexibilidad respecto al riesgo y ventura de los contratos públicos, donde debería contemplarse por vía de principio un régimen compartido de los riesgos y los beneficios derivados del proyecto.

\section{Referencias bibliográficas}

Barbío de Pablos, L., Carrillo, J., Gómez, G., Mesa, M., Millán, C., Montes, F. \& Tarancón, J. (eds.). (2019). La compra pública de innovación en la contratación del sector público. Instituto Nacional de Administración Pública.

Bernal, M. A. (2017). Compra pública de innovación: una aproximación pro-competitiva. En Guillén, J. \& Hernando, M. (coord.), Contratación, competencia y sostenibilidad: pultimas aportaciones desde el derecho administrativo (pp. 83-105). Civitas Reuters.

Gallego, I. (2018). La integración de cláusulas sociales, ambientales y de innovación en la contratación pública. Documentación Administrativa: Nueva Época, 4, 92-113. https://doi.org/10.24965/ da.v0i4.10497

Gimeno, J. M. (2013). Las nuevas directivas -cuarta generación- en materia de contratación pública. Hacia una estrategia eficiente en compra pública. Revista española de Derecho Administrativo, 159, 39-106.

Gómez, J. (2018): La determinación del precio de los contratos públicos con base en el coste. Wolters Kluwer.

Guerrero, C. (27 de abril de 2020). ¿Compra pública de innovación en tiempo de COVID-19? Observatorio de los contratos públicos 2019. Consultado el 13 de febrero de 2021. http://www.obcp.es/opiniones/ compra-publica-de-innovacion-en-tiempo-de-covid-19-la-utilizacionde-las-consultas

Junta Consultiva de Contratación Administrativa del Estado. (2012). Régimen derivado de los contratos I+D, (Informe 13/11). Ministerio de Hacienda.

Ministerio de Ciencia e Innovación. (2021). Estrategia española de Ciencia, Tecnología e Innovación. Ministerio de Ciencia e Innovación.

Miño, A. (2014). La compra pública innovadora en los sistemas europeo y español de contratación pública. En J. Pernas (coord.), Contratación pública estratégica, (pp. 214-248). Aranzadi Thomson Reuters.

Murillo, L. (2013). Compra pública innovadora: fomentando la innovación por el sector público. Actualidad Jurídica Aranzadi, 868, 6.

Organización para la Cooperación y el Desarrollo Económicos \& Oficina de Estadística de las Comunidades Europeas. (2005). Manual de Oslo. Guía para la recogida e interpretación de datos sobre innovación. (3.a ed.). OCDE.

Peñate, C. \& Sánchez, M. (2018). La compra pública innovadora. Análisis regional de la experiencia española. Journal of Regional Research, 40, 79-107.

Pernas, J. (2014). La contratación pública estratégica. Editorial Aranzadi.

Rastrollo, J. (2019). Las conexiones entre contratación administrativa e innovación. Revista de Administración Pública, 208, 450-453.

Tardío, J. (2016). La asociación para la innovación: contrato, procedimiento de adjudicación y libre competencia. Revista Española de Derecho Administrativo, 181, 267-295.

Valcárcel, P. (2018). La innovación como objeto prestacional en los contratos del sector público. La Compra Pública de Innovación. Contratación administrativa práctica. Revista de la contratación administrativa y de los contratistas, 153, 56-68.

Vazquez, F. (2019). Compra pública de innovación. Avanzando hacia la compra pública estratégica. Contratación administrativa práctica: revista de la contratación administrativa y de los contratistas, 159, 8. 